Subscriber access provided by King Abdullah University of Science and Technology Library

\title{
Article
}

\section{Using UCST ionic liquid as a draw solute in forward osmosis to treat high-salinity water}

Yujiang Zhong, Xiaoshuang Feng, Wei Chen, Xinbo Wang, Kuo-Wei Huang, Yves Gnanou, and Zhiping Lai Environ. Sci. Technol., Just Accepted Manuscript • DOI: 10.1021/acs.est.5b03747 • Publication Date (Web): 09 Dec 2015

Downloaded from http://pubs.acs.org on December 16, 2015

\section{Just Accepted}

"Just Accepted" manuscripts have been peer-reviewed and accepted for publication. They are posted online prior to technical editing, formatting for publication and author proofing. The American Chemical Society provides "Just Accepted" as a free service to the research community to expedite the dissemination of scientific material as soon as possible after acceptance. "Just Accepted" manuscripts appear in full in PDF format accompanied by an HTML abstract. "Just Accepted" manuscripts have been fully peer reviewed, but should not be considered the official version of record. They are accessible to all readers and citable by the Digital Object Identifier (DOI®). "Just Accepted" is an optional service offered to authors. Therefore, the "Just Accepted" Web site may not include all articles that will be published in the journal. After a manuscript is technically edited and formatted, it will be removed from the "Just Accepted" Web site and published as an ASAP article. Note that technical editing may introduce minor changes to the manuscript text and/or graphics which could affect content, and all legal disclaimers and ethical guidelines that apply to the journal pertain. ACS cannot be held responsible for errors or consequences arising from the use of information contained in these "Just Accepted" manuscripts. 


\section{Using UCST ionic liquid as a draw solute in forward osmosis to treat high-salinity water}

Yujiang Zhong, Xiaoshuang Feng, Wei Chen, Xinbo Wang, Kuo-Wei Huang, Yves Gnanou,

Zhiping Lai*

Division of Physical Science and Engineering, King Abdullah University of Science and Technology, Thuwal, Saudi Arabia, 23955-6900

Corresponding author: Dr. Zhiping Lai, Zhiping.lai@kaust.edu.sa 


\begin{abstract}
The concept of using a thermo-responsive ionic liquid (IL) with an upper critical solution temperature (UCST) as a draw solute in forward osmosis (FO) was successfully demonstrated here experimentally. A $3.2 \mathrm{M}$ solution of protonated betaine bis(trifluoromethylsulfonyl)imide $\left([\right.$ Hbet $\left.]\left[\mathrm{Tf}_{2} \mathrm{~N}\right]\right)$ was obtained by heating and maintaining the temperature above $56^{\circ} \mathrm{C}$. This solution successfully drew water from high-salinity water up to 3.0 M through FO. When the IL solution cooled to room temperature, it spontaneously separated into a water-rich phase and an IL-rich phase: the water-rich phase was the produced water that contained a low IL concentration, and the IL-rich phase could be used directly as the draw solution in the next cycle of the FO process. The thermal stability, thermal-responsive solubility and UV-vis absorption spectra of the IL were also studied in detail.
\end{abstract}

KEYWORDS: ionic liquid, UCST, forward osmosis, draw solute, desalination, thermalresponsive.

\title{
TOC art
}

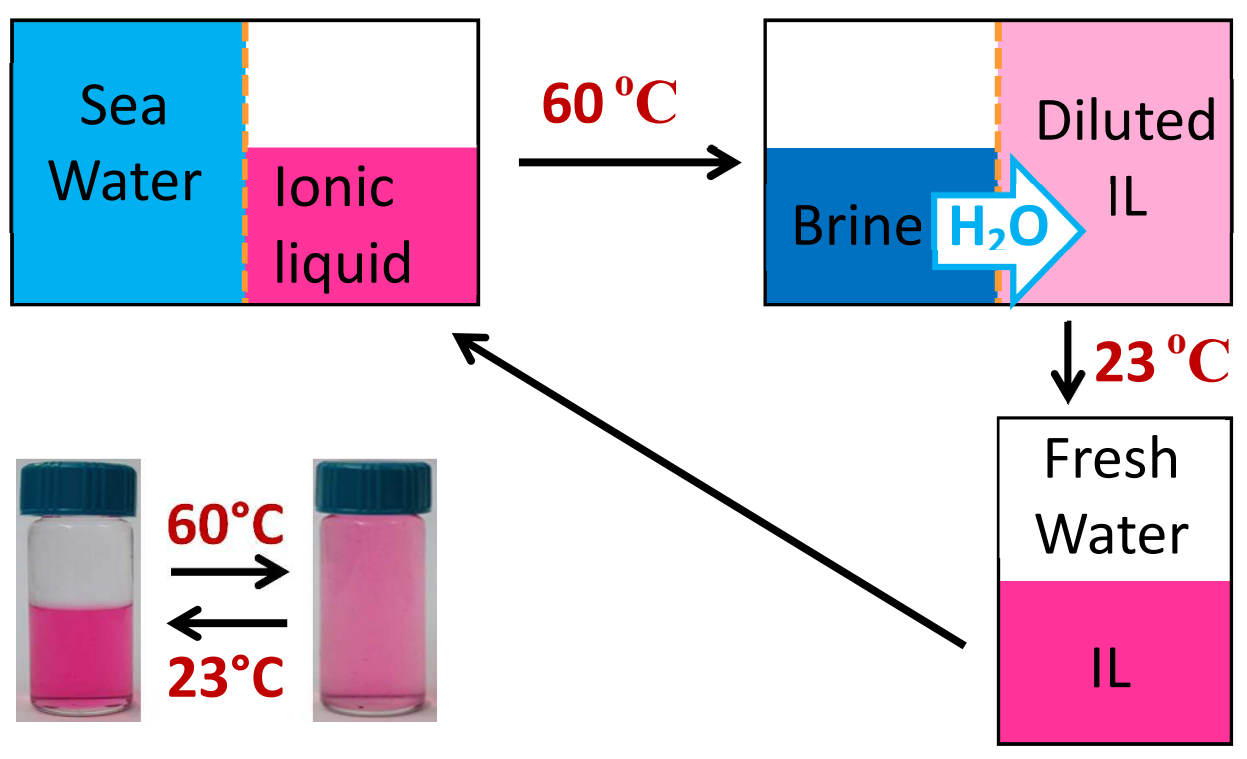




\section{INTRODUCTION}

Our planet is rich with oceans, but of all available water, clean, drinkable water amounts to less than half of $1 \%$. The United Nations (UN) estimates that by $2025,14 \%$ of the world's population will encounter water scarcity. ${ }^{1}$ Seawater desalination and wastewater reuse are two feasible ways of increasing the supply of fresh water. Reverse osmosis (RO) is a seawater desalination method that uses hydraulic pressure as the driving force for separation. Currently, advanced membrane manufacture and engineering applications have made RO a notable process in the global water desalination market. However, high operation pressure is still a key feature of RO which requires to use electricity to drive expensive high pressure pumps. In contrast, forward osmosis (FO) is a natural osmotic process that uses the osmotic pressure difference between the draw solution and the feed solution as its driving force. The FO process has potential to provide higher osmotic pressure difference and therefore higher water flux. By combining with renewable or waste heat resources, the overall cost of energy in FO can be more competitive. In a special FO process, which is named as pressure-retarded osmosis (PRO), energy can be generated from the concentration gradient. ${ }^{2,3}$ Hence, FO is considered not only a technology competitive with RO in water desalination, but also an energy-conversion device. ${ }^{4}$

There are two key components in FO: the semi-permeable membrane and the draw solution. FO was proposed for removing salts from saline water in $1964,{ }^{5}$ but only recently have commercial FO membranes become available and have studies on this area been revitalized. ${ }^{6}$ The other main hindrance to the development of FO is the selection and regeneration of the draw solution. Many compounds have been proposed as draw solutes, including but not limited to inorganic and organic salts, organic acids, sucrose, water-soluble gases, magnetic nanoparticles, stimuliresponsive polymer hydrogels, hydrophilic nanoparticles, fertilizers, polyelectrolytes and 
polyglycol copolymers. ${ }^{7}$ These draw solutes can be regenerated by various approaches, and they have certain advantages; however, they also involve significant drawbacks. For examples, among the proposed draw solutes ammonia-carbon dioxide has a high osmotic efficiency (up to $6 \mathrm{M}$ ) and thus a high draw ability ${ }^{8,9}$ because of the high solubility and relatively low molecular weight (MW). However, the solution is corrosive; the regeneration process requires an intensive energy input, and the produced water has a high ammonia residue, which has limited usage. Magnetic nanoparticles are easily regenerated, and there is no solute crossover as a result of the large size of the nanoparticles, but their draw ability is low because of their large MW. In addition, magnetic nanoparticles lack long-term stability because they tend to agglomerate after several runs of the cycle. ${ }^{10-12}$ Stimuli-responsive polymer hydrogels can entrap a large volume of water due to the high concentration of hydrophilic groups, and water can be released by a reversible volume change or solution-gel phase transitions in response to heating and pressure ${ }^{13-15}$. However, the draw ability is low, and the water extraction and release procedure is slow. Thermo-responsive copolymers and oligomers with a lower critical solution temperature (LCST) were also proposed as novel draw solutes for FO processes. ${ }^{16-18}$ The high MW of the copolymers allows the draw solutes to be easily recovered by microfiltration (MF), but it limits the draw ability. The oligomers can draw water from a feed solution of a $0.60 \mathrm{M} \mathrm{NaCl}$ solution (equivalent to seawater) at most. Hence, the development of a good and novel draw solute is highly desirable.

Ionic liquids (ILs) are ionic, salt-like materials comprising large organic ions with low melting points below $100^{\circ} \mathrm{C}$ under the atmospheric pressure. ${ }^{19-22}$ The much lower melting point of ILs compared with classic inorganic salts can be explained by the Gibbs free energy of fusion, solvation and lattice. ${ }^{23}$ ILs are liquid under standard ambient conditions because the liquid state 
is thermodynamically favorable due to the large size and conformational flexibility of the ions involved, which leads to small lattice enthalpies and large entropy changes that favor melting. ILs are often conductive, highly viscous, thermally stable and minimally combustible. With these special properties, ILs have been widely used in many applications, such as batteries, ${ }^{24,} 25$ catalysis, ${ }^{26-28}$ drug delivery ${ }^{29,30}$ and solvents ${ }^{31-33}$. A recent patent described a FO process to use ILs as draw solutions, but didn't mention the regeneration methods. ${ }^{34}$ Very recently, Cai et al. for the first time proposed to use LCST-type of thermally responsive ILs as draw solutes. ${ }^{35}$ Their results showed that LCST-type of ILs were able to draw water from feed solutions up to a $1.6 \mathrm{M}$ salt concentration at room temperature, and regenerate at high temperature when phase separation was induced.

Here, we describe a process of using a UCST-type IL as a draw solute in FO. The IL used here is protonated betaine bis(trifluoromethylsulfonyl)imide $\left([\mathrm{Hbet}]\left[\mathrm{Tf}_{2} \mathrm{~N}\right]\right){ }^{36}$ The structure is shown in Chart 1. Contrary to the LCST-type IL, the UCST-type IL is immiscible with water at room temperature. Thus, when the IL is mixed with water at room temperature, a two-liquid-phase system will appear. One is the water-rich phase (named as the $\alpha$ phase for short hereafter), and the other is the IL-rich phase (named as the $\beta$ phase for short hereafter). Upon heating above the critical temperature $\left(\mathrm{T}_{\mathrm{c}}\right)$, the two-liquid-phase system will become a uniform IL solution. This thermal-driven phase change is reversible, and it can be fast.
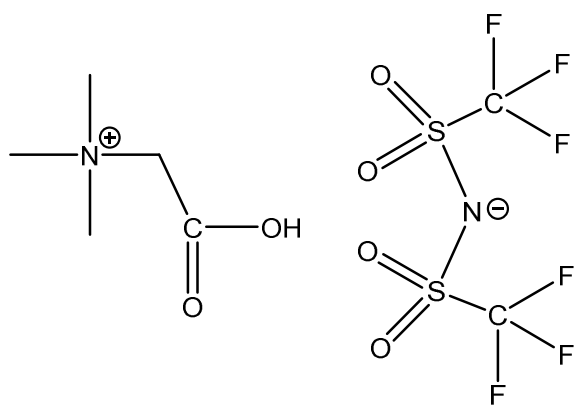
Chart 1. Structure of [Hbet][Tf2 $\mathrm{N}]$.

Based on this thermal-responsive solubility, we can design a process to obtain dilute water from salty water as shown in Scheme 1. First, a highly concentrated IL solution is heated to the degree above the $\mathrm{T}_{\mathrm{c}}$ (approximately $56^{\circ} \mathrm{C}$ ) to become miscible with water, and then it is used as a draw solution to draw water from seawater or another high-salinity water through a FO process. Afterwards, the IL solution is cooled to room temperature, and it automatically separates into the $\alpha$ phase and the $\beta$ phase. The $\alpha$ phase contains a low concentration of IL, which may be further purified by nanofiltration (NF). ${ }^{37}$ The $\beta$ phase contains little water and can be reused directly in the next cycle of the FO process. In our study, $[\mathrm{Hbet}]\left[\mathrm{Tf}_{2} \mathrm{~N}\right]$ was able to extract water from a feed up to $3.0 \mathrm{M} \mathrm{NaCl}$ solution through the $\mathrm{FO}$ process. The high operation temperature is beneficial for achieving a higher water flux.

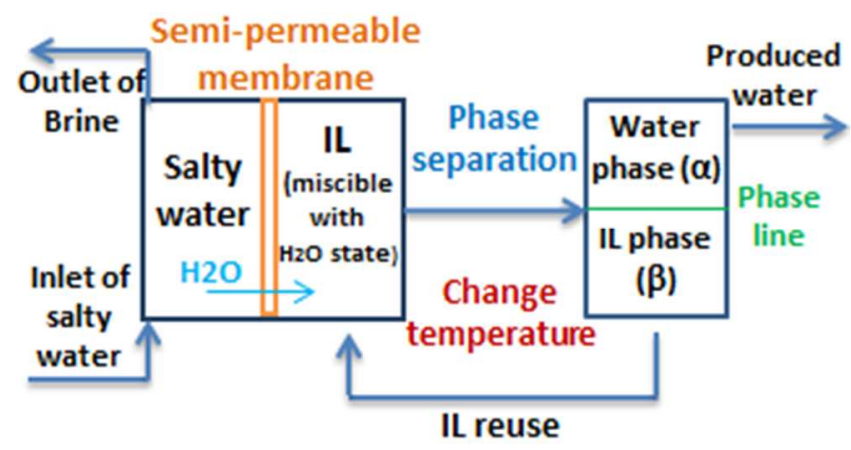

Scheme 1. A novel FO process based on a UCST-IL as the draw solution

\section{MATERIALS AND METHODS}

Materials. Betaine hydrochloride $(>98 \%)$ and lithium bis(trifluoromethanesulfonyl)imide $(>98 \%)$ were purchased from Sung Young Chemical Limited. Sodium chloride $(>99.5 \%)$ was purchased from Sigma-Aldrich. Methyl red was purchased from Fluka. All chemicals were used as received without further purification. Water purified by a Milli-Q (Milli Pore) system was 
used as fresh water in all of the experiments. The FO setup used a Borosilicate Osmosis Cell purchased from Adams \& Chittenden Scientific Glass. The effective membrane area had a diameter of $26 \mathrm{~mm}$. The semi-permeable membrane was YM70ACSP18 purchased from Sterlitech Corporation (produced by Toray Inc.). It is a polyamide type of membrane and usually used as a brackish water reverse osmosis (BWRO) membrane. This membrane was chosen for its high salt rejection rate and good thermal stability. Under the testing conditions suggested by the supplier, i.e., a feed concentration of $2000 \mathrm{ppm}$, a pH of 6.5, and a pressure of $225 \mathrm{psi}$, the typical water flux was 52.2 LMH and the salt rejection rate was $99.8 \%$.

Synthesis of Protonated Betaine Bis(trifluoromethylsulfonyl)imide. A solution of betaine hydrochloride $(1 \mathrm{~mol}, 153.61 \mathrm{~g})$ in $250 \mathrm{~mL}$ of water was added under stirring to $500 \mathrm{~mL}$ of an aqueous solution of lithium bis(trifluoromethylsulfonyl)imide (1 mol, $287.08 \mathrm{~g})$. The mixture was stirred for 1 hour at room temperature, and then the aqueous phase was separated from the IL. The IL phase was washed three times with small amounts of water until no chloride impurities could be detected by the silver nitrate test. ${ }^{36}$ The IL phase contained approximately 88 $\mathrm{wt} \%$ [Hbet][Tf $2 \mathrm{~N}](\mathrm{MW}: 398.33)$ and $12 \mathrm{wt} \%$ water. It can be used directly as a draw solution in FO. A part of the IL phase sample was evaporated at $60^{\circ} \mathrm{C}$ in vacuo on a rotary evaporator for 10 hours to reduce the water content. Then, the sample was further dried in a Lindberg Blue $\mathrm{M}^{\mathrm{TM}}$ vacuum oven at $120^{\circ} \mathrm{C}$ for 6 hours, and yellowish crystals were obtained thereafter (the melting point of $[\mathrm{Hbet}]\left[\mathrm{Tf}_{2} \mathrm{~N}\right]$ is $57^{\circ} \mathrm{C}$, but the liquid compound can be supercooled to room temperature. $[$ Hbet $]\left[\mathrm{Tf}_{2} \mathrm{~N}\right]$ shows a tendency to crystallize rather than to form a glass). ${ }^{36}$ The NMR results of the crystal are as follows: ${ }^{1} \mathrm{H}$ NMR (400 MHz, d6-DMSO, TMS): $\delta=4.276(\mathrm{~s}, 2 \mathrm{H}), 3.204(\mathrm{~s}, 3 \times$ $\left.\mathrm{CH}_{3}\right) .{ }^{13} \mathrm{C}$ NMR (100 MHz, d6-DMSO, TMS): $\delta=166.909$ (COO), 124.797, 121.600, 118.402, 115.205 $\left(2 \times \mathrm{CF}_{3}\right), 63.239\left(\mathrm{~N}-\mathrm{CH}_{2}\right), 53.435\left(3 \times \mathrm{CH}_{3}\right)$. The NMR data confirmed the formation 
of the $[$ Hbet $]\left[\mathrm{Tf}_{2} \mathrm{~N}\right]$ structure. The original NMR spectrum diagrams of the product can be found in supplement $\mathrm{S} 1$.

Analytical Methods. The water flux was measured by weighing the mass of the $\alpha$ phase obtained after phase separation at room temperature. The water flux during the experiments was also monitored by recording the volume change in the feed side of the marked osmosis cell. The water content in the $\beta$ phase was determined using a Karl Fischer Titrator (Mettler Toledo, model C30X). The density was detected by measuring the weight of solution of a certain volume. The IL content in the $\alpha$ phase was determined by conductivity and UV-vis Spectrometers (Cary 5000). The $\mathrm{NaCl}$ concentration was calculated according to the chloride ion concentration analyzed by the Aquakem 250 method. The ${ }^{1} \mathrm{H}$ NMR spectra $(400 \mathrm{MHz})$ and the ${ }^{13} \mathrm{C} \mathrm{NMR}$ spectra $(100 \mathrm{MHz})$ were measured in DMSO by a Bruker Advance 400 spectrometer. The thermal stability of IL was detected using a Thermogravimetric Analyzer (Netzsch, TG 209 F1 with ASC).

\section{RESULTS AND DISCUSSION}

Thermal stability. The FO experiments were designed for operation in a hot water bath $\left(60 \sim 80^{\circ} \mathrm{C}\right)$; thus, the thermal stability of $[\mathrm{Hbet}]\left[\mathrm{Tf}_{2} \mathrm{~N}\right]$ needed to be considered first. The Thermogravimetric Analyzer (TGA) result for $[\mathrm{Hbet}]\left[\mathrm{Tf}_{2} \mathrm{~N}\right]$ is shown in Figure 1. The sample after evaporating at $60^{\circ} \mathrm{C}$ in vacuo was detected by TGA. The temperature range was set from $50^{\circ} \mathrm{C}$ to $600^{\circ} \mathrm{C}$. There were three stages of mass change in this sample: the first started at $64.6^{\circ} \mathrm{C}$ and ended at $167.1^{\circ} \mathrm{C}$ with a $-2.83 \%$ change in mass change; the second started at $302.1{ }^{\circ} \mathrm{C}$ and ended at $404.6^{\circ} \mathrm{C}$ with a $-18.08 \%$ change in mass; the third started at $404.6^{\circ} \mathrm{C}$ and ended at $512.1^{\circ} \mathrm{C}$ with a $-73.65 \%$ change in mass change. The weight loss of the first stage fit well with 
the water content results detected by Karl Fischer Titration $(2.87 \pm 0.08$ wt $\%)$. The second stage started at $302.1^{\circ} \mathrm{C}$; thus, the IL should be stable in the temperature range below $300^{\circ} \mathrm{C}$.

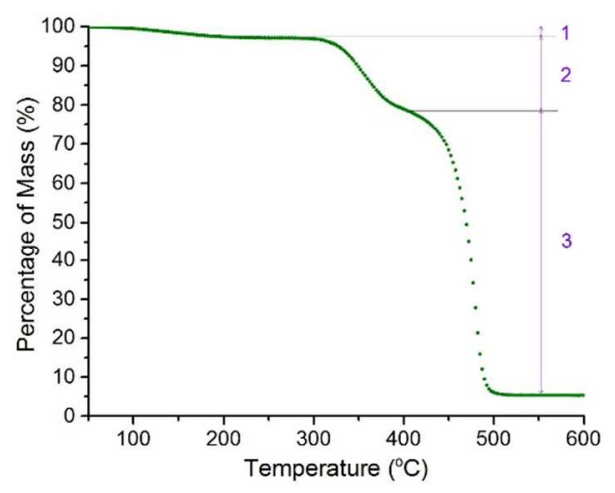

Figure 1. Thermogravimetric analyzer result of [Hbet][Tf2 $\mathrm{N}]$

Thermal-responsive solubility. The thermal responsive solubility of $[\mathrm{Hbet}]\left[\mathrm{Tf}_{2} \mathrm{~N}\right]$ in water is shown in Figure 2. In the mixture of $[\mathrm{Hbet}]\left[\mathrm{Tf}_{2} \mathrm{~N}\right]$ and water, both the $\alpha$ phase and the $\beta$ phase are colorless and transparent. A methyl red dye was used to stain IL for better visualization of the phase boundary. The picture at left shows that at room temperature, the IL is immiscible with water, forming a two-liquid-phase system where the $\beta$ phase is at the bottom due to its higher density. The picture at right shows that when the solution is heated to $60^{\circ} \mathrm{C}$, which is above the $\mathrm{T}_{\mathrm{c}}$ (approximately $56^{\circ} \mathrm{C}$ ), the system becomes a uniform IL solution. This temperature-driven phase change process of [Hbet][Tf2N] is reversible and fast. The liquid-liquid equilibrium phase diagram of $[\mathrm{Hbet}]\left[\mathrm{Tf}_{2} \mathrm{~N}\right]$ with water is shown in Figure 3 . At the room temperature of $23^{\circ} \mathrm{C}$, the saturation concentration of $[\mathrm{Hbet}]\left[\mathrm{Tf}_{2} \mathrm{~N}\right]$ in the $\beta$ phase is approximately $3.2 \mathrm{~mol} / \mathrm{L}(88.3 \mathrm{wt} \%$, the density was detected as $1.45 \mathrm{~g} / \mathrm{cm}^{3}$ ), while in its counterpart the $\alpha$ phase, the saturation concentration of $[\mathrm{Hbet}]\left[\mathrm{Tf}_{2} \mathrm{~N}\right]$ was approximately $0.36 \mathrm{~mol} / \mathrm{L}(13.7 \mathrm{wt} \%$, the density was detected as $\left.1.05 \mathrm{~g} / \mathrm{cm}^{3}\right)$. 


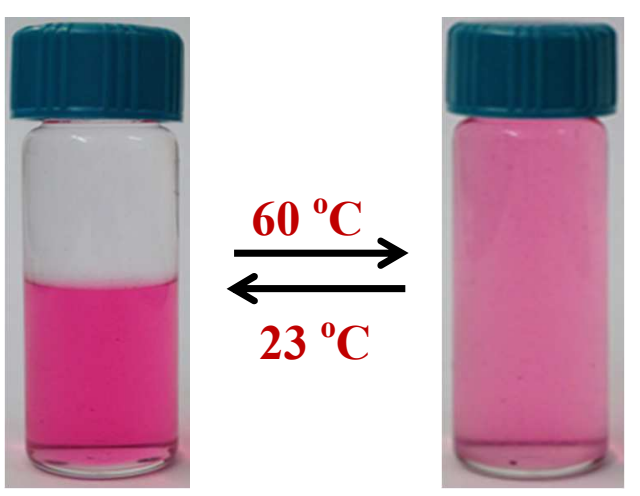

Figure 2. The reversible temperature-driven phase change of the $[\mathrm{Hbet}]\left[\mathrm{Tf}_{2} \mathrm{~N}\right] /$ water system. Methyl red was used to stain IL for better visualization of the phase boundary. Phase separation of the $\alpha$ phase and the $\beta$ phase at room temperature (left); IL miscible with water after being heated to $60^{\circ} \mathrm{C}$ (right).

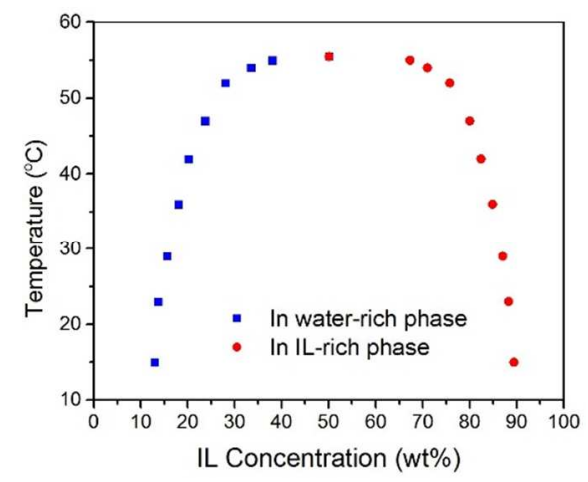

Figure 3. Liquid-liquid equilibrium phase diagram of the $[\mathrm{Hbet}]\left[\mathrm{Tf}_{2} \mathrm{~N}\right] /$ water system.

UV-vis Absorption Property. The concentration of $[\mathrm{Hbet}]\left[\mathrm{Tf}_{2} \mathrm{~N}\right]$ in both the $\alpha$ phase and the $\beta$ phase are important in this study. As a feature of $[\mathrm{Hbet}]\left[\mathrm{Tf}_{2} \mathrm{~N}\right]$, visible and ultraviolet spectroscopy is a good method for detecting the concentration. The UV-vis Absorption Spectra of the dilute $[\mathrm{Hbet}]\left[\mathrm{Tf}_{2} \mathrm{~N}\right]$ water solution is shown in Figure 4. The maximum absorption wavelength $\left(\lambda_{\text {Max }}\right)$ was $187 \mathrm{~nm}$ (Figure $\left.4 \mathrm{~A}\right)$, and the absorbance in $\lambda_{\text {Max }}$ with different concentrations 
fit very well with a linear relationship (Figure $4 \mathrm{~B}$ ). With this relationship, the $[\mathrm{Hbet}]\left[\mathrm{Tf}_{2} \mathrm{~N}\right]$ concentration could be detected quickly and accurately by a UV-vis spectrometer.
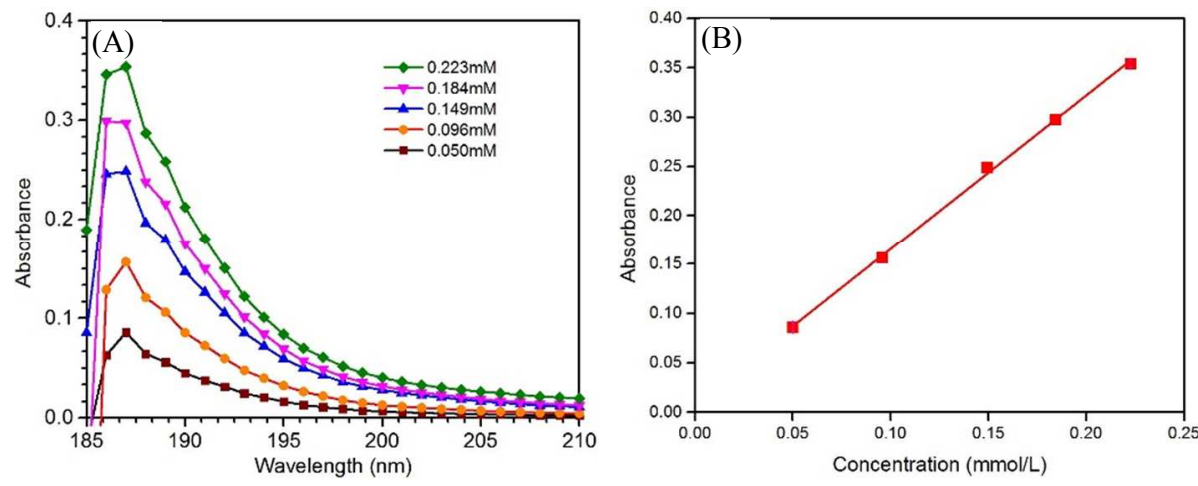

Figure 4. UV-vis absorption spectra of the dilute $[\mathrm{Hbet}]\left[\mathrm{Tf}_{2} \mathrm{~N}\right]$ water solution. (A) The absorption peak range of different concentrations of the [Hbet][Tf2 $\mathrm{N}]$ water solution; (B) absorbance of different concentrations in $\lambda_{\max }$, which is $187 \mathrm{~nm}$ in (A).

Draw ability in FO process. Theoretically, any semi-permeable membrane that selectively allow water to pass through at a much higher rate than other components could be used in the FO process, but with different performance, such as water flux, salt rejection and stability. There are three groups of commercial semi-permeable membranes for water treatments, seawater reverse osmosis (SWRO) membranes, BWRO membranes and FO membranes. In general, SWRO membranes have higher rejection rate for $\mathrm{NaCl}$ but low flux for water compared to $\mathrm{BWRO}$ membranes. Commercial FO membranes such as the HTIC CA membrane can provide a higher water flux than BWRO membranes, but lower salt rejection rate and low thermal stability. A polyamide type of BWRO membrane YM70ACSP18 provided by Toray Inc. was used in this study to demonstrate the concept of using UCST-type ILs in FO processes. Although the water flux of this membrane is relatively low, however, it upholds high salt rejection and stable performance in hot IL solution $\left(60 \sim 80^{\circ} \mathrm{C}\right)$. The IL draw solution used in this study is the 
saturated $\beta$ phase at room temperature $\left(23^{\circ} \mathrm{C}\right)$, which contains $88.3 \mathrm{wt} \%$ [Hbet][Tf $\left.2 \mathrm{~N}\right]$ and $11.7 \mathrm{wt} \%$ water. The molar concentration is $3.2 \mathrm{M}$. In all our experiments, the active layer of the membrane was faced to the feed solution.

The water flux in a typical FO process was first tested with DI water as the feed and concentrated IL $(3.2 \mathrm{M})$ as the draw solution. Both IL and DI water were first warmed to the target temperature before being poured to the feed and draw side of the FO instrument, respectively, and then the entire instrument was placed in a hot water bath to maintain the target temperature. The amount of water passing through the membrane during the FO process could be monitored directly from the volume marks on the glass cell. Figure 5 shows the amount of water drawn from the feed side to the IL side at different times and temperatures. At each temperature, the amount of water increased linearly with time, indicating that the FO process was under steady state. Increasing the operation temperature had a positive influence on the water flux across the membrane. The improvement in water passing was approximately $5 \mathrm{ml}$ per 10 hours per $10^{\circ} \mathrm{C}$ temperature increase. The concentration of $[\mathrm{Hbet}]\left[\mathrm{Tf}_{2} \mathrm{~N}\right]$ in the feed side was detected after each experiment. The crossover rate of the IL was found to be $7.06,14.63$ and $19.12 \mathrm{mmol} / \mathrm{m}^{2} / \mathrm{h}$ at $60^{\circ} \mathrm{C}, 70^{\circ} \mathrm{C}$ and $80^{\circ} \mathrm{C}$, respectively. Although the crossover rate of the IL increased with temperature, however, because the very little amount of the detected IL in the feed side after the experiment (all less than $1 \mathrm{mmol} / \mathrm{L}$ ), hence rejection rate of IL is high, which were $99.989 \%$, $99.976 \%$ and $99.971 \%$, at three temperatures, respectively. 


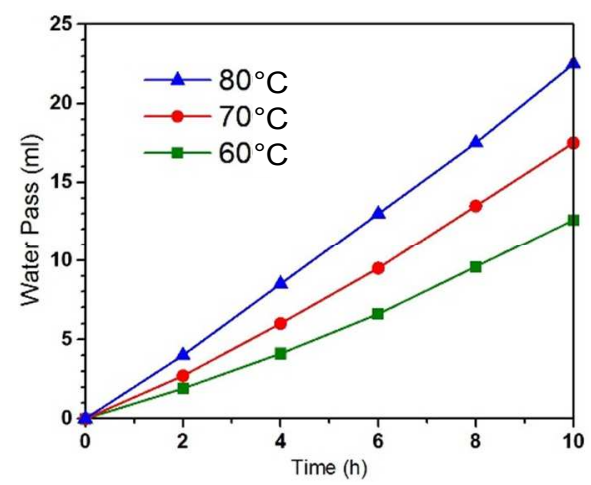

Figure 5. The amount of water pass with time at different temperatures

The draw ability of the concentrated $[$ Hbet $]\left[\mathrm{Tf}_{2} \mathrm{~N}\right]$ solution $(3.2 \mathrm{M})$ in the FO process was tested with different $\mathrm{NaCl}$ solutions as the feed ranging from 0 (i.e., DI water) to $3.0 \mathrm{M}$. The operation temperature was set constant at $60^{\circ} \mathrm{C}$. The experimental procedure was similar to the description in the previous paragraph. When the experiments stopped after 10 hours, the draw solution was poured to a separation funnel and kept still at room temperature for 2 hours to cool the solution and complete the phase separation. The obtained $\alpha$ and $\beta$ phases were analyzed to obtain the mass and the concentration of both $\mathrm{NaCl}$ and IL, and the results are listed in Table 1. Figure 6 shows the water flux at different feed concentrations. In comparison, Figure 6 also shows the water flux when a $3.2 \mathrm{M} \mathrm{NaCl}$ solution was used as the draw solution at room temperature $\left(23^{\circ} \mathrm{C}\right)$ and at $60^{\circ} \mathrm{C}$. The concentrated IL, i.e., the $\beta$ phase, can draw water not only from the seawater level $(0.6 \mathrm{M})$ but also from high-salinity water up to $3.0 \mathrm{M}$ in a measurable amount. When the concentration of the feed solution increased from 0 to $0.17 \mathrm{M}$ (equivalent to $\sim 1 \mathrm{wt} \%$ ), the water flux decreased sharply, but further increasing the feed concentration the reduced water flux more slowly. The $3.2 \mathrm{M} \mathrm{NaCl}$ solution showed similar trends to the concentrated IL. The water flux of the concentrated IL at $60^{\circ} \mathrm{C}$ was higher than that of the $3.2 \mathrm{M} \mathrm{NaCl}$ solution at room temperature but lower than the $3.2 \mathrm{M} \mathrm{NaCl}$ solution at $60^{\circ} \mathrm{C}$. The $\mathrm{NaCl}$ concentration 
detected in the produced water, i.e., the $\alpha$ phase, increased when the concentration of the feed solution increased, while the IL concentration detected in the $\alpha$ phase was kept constant approximately $0.36 \mathrm{M}$, which is close to its saturation concentration. The $\beta$ phase in this study was reused as the draw solution directly. As shown in Table $1, \mathrm{NaCl}$ was also detected in the $\beta$ phase after FO process and phase separation, but the concentration was much lower (less than one tenth) than that in the $\alpha$ phase. If the salt accumulated in the $\beta$ phase, it could be easily washed away by DI water as described in the previous synthesis section (it will cause some loss of the IL though).

Table 1. The composition data of the FO experiments with different concentrations of feed solution.

\begin{tabular}{|c|c|c|c|c|c|c|c|c|c|c|}
\hline $\begin{array}{l}\mathrm{NaCl} \text { in } \\
\text { Feed } \\
(\mathrm{mol} / \mathrm{L})\end{array}$ & $\begin{array}{l}\text { Total } \\
\text { mass } \\
(\mathrm{g})\end{array}$ & $\begin{array}{c}\text { Mass of } \\
\alpha \\
(\mathrm{g})\end{array}$ & $\begin{array}{l}\text { Water } \\
\text { flux } \\
\text { (LMH) }\end{array}$ & $\begin{array}{c}\mathrm{NaCl} \text { in } \\
\alpha \\
(\mathrm{mol} / \mathrm{L})\end{array}$ & $\begin{array}{l}\text { IL in } \alpha \\
(\mathrm{mol} / \mathrm{L})\end{array}$ & $\begin{array}{c}\text { Mass } \\
\text { of } \beta \\
(\mathrm{g})\end{array}$ & $\begin{array}{l}\mathrm{NaCl} \text { in } \beta \\
(\mathrm{mmol} / \mathrm{L})\end{array}$ & $\begin{array}{c}\mathrm{H}_{2} \mathrm{O} \text { in } \\
\beta \\
(\mathrm{wt} \%)\end{array}$ & $\begin{array}{l}\mathrm{NaCl} \\
\text { rejection } \\
(\%)\end{array}$ & $\begin{array}{l}\text { Salt flux } \\
\left(\mathrm{g} / \mathrm{m}^{2} / \mathrm{h}\right)\end{array}$ \\
\hline 0.00 & 169.28 & 12.03 & 2.27 & 1 & 0.3557 & 157.25 & 1 & 12.675 & 1 & 1 \\
\hline 0.17 & 173.43 & 4.53 & 0.85 & 0.020 & 0.3358 & 168.90 & 1.515 & 14.608 & 88.41 & 0.98 \\
\hline 0.60 & 165.71 & 2.64 & 0.50 & 0.079 & 0.3475 & 163.07 & 5.431 & 13.603 & 86.79 & 2.31 \\
\hline 1.00 & 162.50 & 2.34 & 0.44 & 0.180 & 0.3699 & 160.16 & 10.568 & 12.808 & 81.98 & 4.65 \\
\hline 2.00 & 158.60 & 1.35 & 0.25 & 0.259 & 0.3655 & 157.25 & 10.256 & 14.524 & 87.03 & 3.86 \\
\hline 3.00 & 153.63 & 0.75 & 0.14 & 0.266 & 0.3708 & 152.88 & 7.157 & 13.943 & 91.14 & 2.17 \\
\hline
\end{tabular}

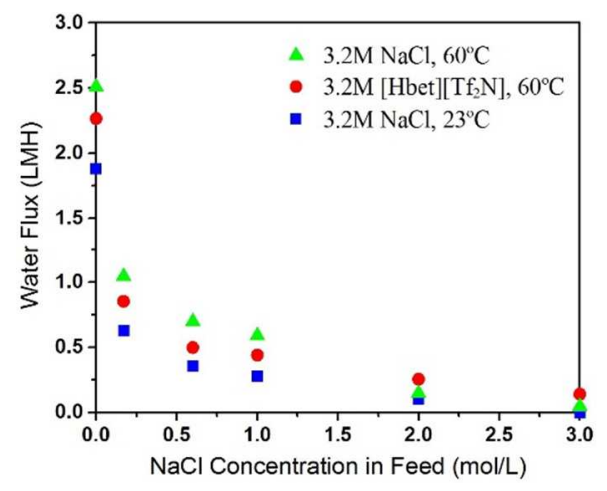

Figure 6. Comparison of water flux at different feed concentrations when the $3.2 \mathrm{M}$ IL solution and $3.2 \mathrm{M} \mathrm{NaCl}$ solution were used as the draw solution. The series of IL as the draw solution 
was tested at $60^{\circ} \mathrm{C}$, while the series of $3.2 \mathrm{M} \mathrm{NaCl}$ as the draw solution was tested at $23^{\circ} \mathrm{C}$ and $60^{\circ} \mathrm{C}$.

One disadvantage of $[\mathrm{Hbet}]\left[\mathrm{Tf}_{2} \mathrm{~N}\right]$ is its relatively high saturation concentration in the $\alpha$ phase at room temperature. Hence, the $\alpha$ phase will need further purification by either RO or NF in order to reach the drinkable water level. Obviously, the lower the saturation concentration in the $\alpha$ phase, the lower the energy required in the further purification process. Therefore, reducing the saturation concentration in the $\alpha$ phase would be the key research direction for further improving the process. Nevertheless, based on the results in Table 1, a rough estimation of the energy consumption was attempted for different combinations of desalination processes including a standard seawater desalination process (SWRO) as the base case, a FO + SWRO, a FO + NF, a $\mathrm{FO}+\mathrm{BWRO}$, and a FO $+\mathrm{NF}+\mathrm{BWRO}$. The detail descriptions of each case are provided in the supplementary S2. The energy is calculated by a simulation tool provided by Toray DS2. ${ }^{38}$ Comparing to the SWRO base case, an additional thermal energy of $44.15 \mathrm{KWH}$ per ton of water is required for the FO process, while the electricity for the RO process can be reduced from 2.96 to $0.78 \mathrm{KWH}$ per ton of water. This demonstrates the concept of the FO process which is to utilize renewable or waste thermal energy to replace the more expensive electrical energy in order to achieve a more economic competitive desalination process.

In conclusion, we studied here for the first time the use of a UCST-type IL as a novel draw solute in FO as proof of the concept. Our results showed that a UCST-type IL, [Hbet][Tf $2 \mathrm{~N}]$, was able to draw water from a high salinity solution up to $3.0 \mathrm{M} \mathrm{NaCl}$ solution, and the IL draw solution can be easily regenerated by thermal-driven phase separation. The $\mathrm{T}_{c}$ of $[\mathrm{Hbet}]\left[\mathrm{Tf} \mathrm{f}_{2} \mathrm{~N}\right]$ is approximately $56^{\circ} \mathrm{C}$, which is relatively low and would be beneficial for energy conservation. 
Solar energy would be a good thermal resource for this process, and this novel thermal change FO process has special potential benefit for the desert area such as Saudi Arabia which possesses a huge potential for solar energy and has limited supply of fresh water. Compared to reported LCST-type IL, the UCST-type IL requires the FO process to be conduct at higher temperature. Conducting the FO process at higher temperatures in one hand can help increase the water flux. The draw ability is much higher, which is beneficial to improve the water recovery rate. However, from the other hand it also raise a concern of the membrane stability. The TorayC YM70ACSP18 type of BWRO membrane showed good stability during our experimental studies, although its long-term stability still needs to be investigated. However, this concern can also be addressed by the recent development of inorganic membranes such as zeolite, carbon nanotube and graphene, etc., which have already shown good performance in RO and FO application. ${ }^{39-42}$ The other issue of $[\mathrm{Hbet}]\left[\mathrm{Tf}_{2} \mathrm{~N}\right]$ is its relative high concentration in the $\alpha$ phase. Reducing the saturation concentration in the $\alpha$ phase would increase the potential and eventually make the procedure studied in this work more feasible for seawater desalination. This achievement may be possible by optimizing the structure of the IL.

\section{SUPPORTING INFORMATION}

Detailed NMR results and linear relationship of the absorbance in $\lambda_{\text {Max }}$ with different concentrations of $[\mathrm{Hbet}]\left[\mathrm{Tf}_{2} \mathrm{~N}\right]$. This material is available free of charge via the Internet at http://pubs.acs.org.

\section{AUTHOR CONTRIBUTIONS}

Ms. Yujiang Zhong conducted most of the FO experiments and calculations and prepared the manuscript. Dr. Xiaoshuang Feng, Prof. Yves Gananou and Prof. Zhiping Lai contributed to the 
original idea. Dr. Wei Chen prepared membranes and helped in the FO experiments. Dr. Xinbo Wang and Prof. Kuo-Wei Huang provide technical suggestions to the molecular structure of the IL. Prof. Zhiping Lai supervised the project and revised the manuscript.

\section{ACKNOWLEDGMENT}

We would like to thank Dr. NorEddine Ghaffour for helpful discussions. Funding is provided by KAUST baseline (BAS/1/1723-01-01) and KAUST CRG project (URF/1/1723-01-01)

\section{ABBREVIATIONS}

IL, ionic liquid; UCST, upper critical solution temperature; FO, forward osmosis; [Hbet][Tf2N], protonated betaine bis(trifluoromethylsulfonyl)imide; UN, United Nations; RO, reverse osmosis; LCST, lower critical solution temperature; MW, molecular weight; MF, microfiltration; DI, deionized; $\mathrm{T}_{\mathrm{c}}$, critical temperature; the $\alpha$ phase, the water phase of $[\mathrm{Hbet}]\left[\mathrm{Tf}_{2} \mathrm{~N}\right]$ and water mixture in phase equilibrium; the $\beta$ phase, the IL phase of $\left.\left[\mathrm{Hbet}_{[}\right] \mathrm{Tf}_{2} \mathrm{~N}\right]$ and water mixture in phase equilibrium; NF, nanofiltration; BWRO, brackish water reverse osmosis; NMR, nuclear magnetic resonance; UV-vis, ultraviolet and visible spectroscopy; TGA, thermogravimetric analyzer; $\lambda_{\max }$, the maximum UV-vis absorption wave-length.

\section{REFERENCES}

1. Combs, S. Texas Water Report: Going Deeper for the Solution; Texas Comptroller of Public Accounts: Austin, Texas, 2014.

2. Norman, R. S., Water salination: A source of energy. Science 1974, 186, 350-352.

3. Achilli, A.; Cath, T. Y.; Childress, A. E., Power generation with pressure retarded osmosis: An experimental and theoretical investigation. J. Membr. Sci. 2009, 343, (1-2), 42-52.

4. Cath, T. Y.; Childress, A. E.; Elimelech, M., Forward osmosis: principles, applications, and recent developments. J. Membr. Sci. 2006, 281, 70-87.

5. Neff, R. A. Solvent extractor. US patent 3130156, 1964.

6. Zhao, S. F.; Zou, L.; Tang, C. Y. Y.; Mulcahy, D., Recent developments in forward osmosis: Opportunities and challenges. J. Membr. Sci. 2012, 396, 1-21.

7. Ge, Q. C.; Ling, M. M.; Chung, T. S., Draw solutions for forward osmosis processes: Developments, challenges, and prospects for the future. J. Membr. Sci. 2013, 442, 225-237. 
8. McCutcheon, J. R.; McGinnis, R. L.; Elimelech, M., A novel ammonia—carbon dioxide forward (direct) osmosis desalination process. Desalination 2005, 174, (1), 1-11.

9. McCutcheon, J. R.; McGinnis, R. L.; Elimelech, M., Desalination by ammonia-carbon dioxide forward osmosis: Influence of draw and feed solution concentrations on process performance. J. Membr. Sci. 2006, 278, (1-2), 114-123.

10. Ling, M. M.; Wang, K. Y.; Chung, T. S., Highly water-soluble magnetic nanoparticles as novel draw solutes in forward osmosis for water reuse. Ind. Eng. Chem. Res. 2010, 49, (12), 5869-5876.

11. Ge, Q.; Su, J.; Chung, T. S.; Amy, G., Hydrophilic superparamagnetic nanoparticles: Synthesis, characterization, and performance in forward osmosis processes. Ind. Eng. Chem. Res. 2011, 50, (1), 382-388.

12. Bai, H. W.; Liu, Z. Y.; Sun, D. D., Highly water soluble and recovered dextran coated Fe3O4 magnetic nanoparticles for brackish water desalination. Sep. Purif. Technol. 2011, 81, (3), 392-399.

13. Li, D.; Zhang, X.; Yao, J.; Simon, G. P.; Wang, H. T., Stimuli-responsive polymer hydrogels as a new class of draw agent for forward osmosis desalination. Chem. Commun. 2011, 47, (6), 1710-1712.

14. Li, D.; Zhang, X.; Yao, J.; Zeng, Y.; Simon, G. P.; Wang, H. T., Composite polymer hydrogels as draw agents in forward osmosis and solar dewatering. Soft Matter 2011, 7, (21), 10048-10056.

15. Razmjou, A.; Barati, M. R.; Simon, G. P.; Suzuki, K.; Wang, H. T., Fast Deswelling of Nanocomposite Polymer Hydrogels via Magnetic Field-Induced Heating for Emerging FO Desalination. Environ. Sci. Technol. 2013, 47, (12), 6297-6305.

16. Kim, J. J.; Chung, J. S.; Kang, H.; Yu, Y. A.; Choi, W. J.; Kim, H. J.; Lee, J. C., Thermoresponsive copolymers with ionic group as novel draw solutes for forward osmosis processes. Macromol. Res. 2014, 22, (9), 963-970.

17. Noh, M.; Mok, Y.; Lee, S.; Kim, H.; Lee, S. H.; Jin, G. W.; Seo, J. H.; Koo, H.; Park, T. H.; Lee, Y., Novel lower critical solution temperature phase transition materials effectively control osmosis by mild temperature changes. Chem. Commun. 2012, 48, (32), 3845-3847.

18. Mok, Y.; Nakayama, D.; Noh, M.; Jang, S.; Kim, T.; Lee, Y., Circulatory osmotic desalination driven by a mild temperature gradient based on lower critical solution temperature (LCST) phase transition materials. Phys. Chem. Chem. Phys. 2013, 15, (44), 19510-19517.

19. Weingaertner, H., Understanding ionic liquids at the molecular level: Facts, problems, and controversies. Angew. Chem. Int. Edit 2008, 47, (4), 654-670.

20. Welton, T., Room-temperature ionic liquids. Solvents for synthesis and catalysis. Chem. Rev. 1999, 99, (8), 2071-2083.

21. Wasserscheid, P.; Keim, W., Ionic liquids - New "solutions" for transition metal catalysis. Angew. Chem. Int. Edit 2000, 39, (21), 3772-3789.

22. Zhang, S. J.; Sun, N.; He, X. Z.; Lu, X. M.; Zhang, X. P., Physical properties of ionic liquids: Database and evaluation. J. Phys. Chem. Ref. Data 2006, 35, (4), 1475-1517.

23. Krossing, I.; Slattery, J. M.; Daguenet, C.; Dyson, P. J.; Oleinikova, A.; Weingartner, H., Why are ionic liquids liquid? A simple explanation based on lattice and solvation energies. $J$. Am. Chem. Soc. 2006, 128, (41), 13427-13434.

24. Armand, M.; Endres, F.; MacFarlane, D. R.; Ohno, H.; Scrosati, B., Ionic-liquid materials for the electrochemical challenges of the future. Nat. Mater. 2009, 8, (8), 621-629. 
25. Hamilton, T., Betting on a metal-air battery breakthrough. Technol. Rev. 2009.

26. Walker, A. J.; Bruce, N. C., Cofactor-dependent enzyme catalysis in functionalized ionic solvents. Chem. Commun. 2004, (22), 2570-2571.

27. Wheeler, C.; West, K. N.; Liotta, C. L.; Eckert, C. A., Ionic liquids as catalytic green solvents for nucleophilic displacement reactions. Chem. Commun. 2001, (10), 887-888.

28. Sheldon, R., Catalytic reactions in ionic liquids. Chem. Commun. 2001, (23), 2399-2407.

29. Stoimenovski, J.; MacFarlane, D. R.; Bica, K.; Rogers, R. D., Crystalline vs. Ionic Liquid Salt Forms of Active Pharmaceutical Ingredients: A Position Paper. Pharm. Res. 2010, 27, (4), 521-526.

30. Postleb, F.; Stefanik, D.; Seifert, H.; Giernoth, R., BIOnic Liquids: Imidazolium-based Ionic Liquids with Antimicrobial Activity. Z. Naturforsch. B: Chem. Sci. 2013, 68, (10), 11231128.

31. Rogers, R. D.; Seddon, K. R., Ionic liquids - Solvents of the future? Science 2003, 302, (5646), 792-793.

32. Suresh; Sandhu, J. S., Recent advances in ionic liquids: green unconventional solvents of this century: part I. Green Chem. Lett. Rev. 2011, 4, (4), 289-310.

33. Suresh; Sandhu, J. S., Recent advances in ionic liquids: green unconventional solvents of this century: part II. Green Chem. Lett. Rev. 2011, 4, (4), 311-320.

34. Bharwada, U. J.; Farr, I. V. Use of novel draw solutes and combinations thereof to improve performance of a forward osmosis system and process. US patent 2013/0256228 A1, 2013.

35. Cai, Y. F.; Shen, W. M.; Wei, J.; Chong, T. H.; Wang, R.; Krantz, W. B.; Fane, A. G.; Hu, $\mathrm{X}$., Energy-efficient desalination by forward osmosis using responsive ionic liquid draw solutes. Environ. Sci.: Water Res. Technol. 2015, 1, (3), 341-347.

36. Nockemann, P.; Thijs, B.; Pittois, S.; Thoen, J.; Glorieux, C.; Van Hecke, K.; Van Meervelt, L.; Kirchner, B.; Binnemans, K., Task-specific ionic liquid for solubilizing metal oxides. $J$. Phys. Chem. B 2006, 110, (42), 20978-20992.

37. Fernández, J. F.; Bartel, R.; Bottin-Weber, U.; Stolte, S.; Thöming, J., Recovery of Ionic Liquids from Wastewater by Nanofiltration. J. Membr. Sci. Technol. 2011, S:4.

38. https://ap8.toray.co.jp/toraywater/

39. Humplik, T.; Lee, J.; O’Hern, S. C.; Fellman, B. A.; Baig, M. A.; Hassan, S. F.; Atieh, M. A.; Rahman, F.; Laoui, T.; Karnik, R.; Wang, E. N., Nanostructured materials for water desalination. Nanotechnology 2011, 22, (29), 292001.

40. You, S.; Tang, C.; Yu, C.; Wang, X.; Zhang, J.; Han, J.; Gan, Y.; Ren, N., Forward Osmosis with a Novel Thin-Film Inorganic Membrane. Environ. Sci. Technol. 2013, 47, (15), 87338742.

41. Goh, P. S.; Ismail, A. F.; Ng, B. C., Carbon nanotubes for desalination: Performance evaluation and current hurdles. Desalination 2013, 308, 2-14.

42. Das, R.; Ali, M. E.; Hamid, S. B. A.; Ramakrishna, S.; Chowdhury, Z. Z., Carbon nanotube membranes for water purification: A bright future in water desalination. Desalination 2014, 336, 97-109. 